\title{
Perfil del retornado de segunda generación en Galicia a través de historias de vida*
}

\author{
Margarita Pino Juste \\ Universidad de Vigo \\ Departamento de Didáctica, Organización Escolar y Métodos de Investigación \\ mpino@uvigo.es
}

Carmen Verde Diego

Universidad de Vigo

Escuela Universitaria de Trabajo Social

carmenverde@uvigo.es

Recibido: 19-12-2007

Aceptado: 30-07-2008

\section{Resumen}

El artículo es el resultado de una investigación sobre la emigración de retorno de segunda generación en Galicia (España). Se comienza con una breve introducción al tema y se continúa exponiendo el marco conceptual del retorno: las teorías explicativas de este fenómeno, las tipologías que lo clasifican y una caracterización genérica de los emigrantes retornados en Galicia. Además, se realiza una presentación del marco metodológico del estudio. Este apartado sirve de contextualización a la última parte del artículo, donde se presentan los resultados específicos obtenidos de la investigación realizada.

Palabras clave: emigración de retorno, movimientos migratorios, tipología de emigrantes, necesidades del emigrante.

\section{Abstract. Profile of Second Generation Returned Emigrants in Galicia Using Life Stories}

This article is the result of an investigation on second generation returned emigrants in Galicia (Spain). We begin with a brief introduction, and then present a conceptual framework which includes different explanatory theories of emigrants' return, as well as some typologies to classify different kinds of return, and a generic characterization of the returned emigrants in Galicia. We also present the methological frame of the study, as a contextualization to the last part of the article where we discuss the specific results obtained in the research.

Key words: return emigration, migratory movements, typology of emigrants, needs of the emigrant.

* Este artículo está subvencionado por la Secretaría General de Investigación y Desarrollo de la Xunta de Galicia, a través del proyecto de investigación PGIDITO30501PR. Esta investigación forma parte de un estudio más amplio, realizado por las mismas investigadoras, que analiza, en general, el retorno a Galicia y su impacto desde la primera generación de retornados hasta la generación de sus hijos y nietos. 


\section{Sumario}
1. Presentación y pertinencia del tema
4. Resultados de la investigación
2. Teorías e investigaciones sobre
5. Conclusiones
el retorno
6. Referencias bibliográficas

3. Metodología de la investigación

\section{Presentación y pertinencia del tema}

Los movimientos migratorios, importantes para la historia de cualquier país, han sido determinantes durante el siglo XX para España y, en especial, para Galicia.

Sobre la emigración española y gallega, tanto transoceánica como europea, así como de las razones que provocaron cada una de ellas, y las repercusiones que comportaron, existen numerosas investigaciones, ya que "pocos hechos están tan documentados y próximos como la larga tradición de España como emisor de emigrantes» (Criado, 2001: 45).

Los modelos explicativos sobre la emigración española — de entre las teorías generales sobre la emigración - inciden especialmente en explicar los motivos laborales, económicos ${ }^{1}$, sociales y políticos que provocaron la salida de millones de españoles al extranjero durante décadas: «Se calcula que entre 1959 y 1974 más de 2,5 millones, entre trabajadores y familiares, emigraron a otros países europeos, lo que supuso cerca de un $6 \%$ de la población general y un $10 \%$ de la población activa» (Criado, 2001: 45) ${ }^{2}$. Sin embargo, existen muy pocos estudios sobre las causas y las consecuencias del retorno a los países de origen.

Si los movimientos migratorios fueron importantes para España, en Galicia determinaron su historia desde el siglo XIX, hasta el punto de que en muchos países, especialmente iberoamericanos, se llama "gallegos» a todos los españoles emigrantes, aunque no procedan de Galicia.

A partir de esta década, podemos distinguir tres grandes grupos de inmigrantes en España: por una parte, los extranjeros comunitarios (30\% más o menos del total de extranjeros residentes) instalados en España por motivos laborales (implantación de empresas europeas que traen consigo a sus directivos, por ejemplo), o que residen habitualmente en la costa mediterránea, al jubilarse (sobre todo alemanes, ingleses y holandeses), o que se emplazan aquí por razones de estudio, por matrimonio, etc.

El segundo gran grupo de extranjeros lo constituyen los extracomunitarios, cuya residencia en España se explica, en general, a partir de motivos labo-

1. El push and pull factors, esgrimido por la perspectiva neoclásica y el enfoque del equilibrio, enmarcados en el paradigma funcionalista, siguen siendo, hoy en día, usados como explicación de los movimientos migratorios. La perspectiva histórico-estructural para quien la emigración es una cuestión de clase y de relaciones laborales también ha intentado explicar las razones de la emigración (Criado, 2001: 30-44; Blanco, 2000).

2. Véase, entre otros, a Vilar (1975), De Miguel y otros (1986) y Blanco (2000). 
rales y económicos, en especial para aquéllos procedentes de Iberoamérica, África y Asia (60\% más o menos de la inmigración española). En ocasiones, se reduce el concepto de «inmigrantes» a este grupo.

El tercer grupo de inmigrantes lo conformarían españoles emigrados, sus cónyuges, hijos y nietos, quienes regresan de nuevo a residir en España tras su periplo migratorio. Muchos de ellos han perdido su nacionalidad de origen y son, por lo tanto, legalmente, extranjeros, al igual que los demás. La legislación que regula sus deberes y derechos en España es la Ley de extranjería ${ }^{3}$.

Por lo tanto, algunos «extranjeros» que llegan a España son, en realidad, emigrantes retornados, los cuales, en la diáspora, y por las razones que fuese, pudieron haber perdido la nacionalidad española ${ }^{4}$. También se considera a los hijos y nietos de estos primeros emigrantes como "emigrantes retornados", de acuerdo con la legislación relativa a la nacionalidad. Pero si estos descendientes no tienen la nacionalidad española, tardarán entre un año y tres años en recuperarla — si así lo solicitan—, y serán considerados legalmente «extranjeros» mientras no se resuelva su expediente de nacionalización.

En Galicia, el fenómeno de la «inmigración», tal como manifiesta Hernández Borge (2003: 158-159), se asocia, en mayor medida que en el resto de España, a este último grupo de inmigrantes, los «emigrantes retornados».

En nuestro estudio, se intenta definir el perfil del emigrante retornado y describir los motivos para la emigración y el retorno, señalando las dificultades que presenta este colectivo, con el fin de diseñar programas de reinserción social y laboral que facilite su rápida y exitosa integración.

Para ello, consideramos importante realizar una breve aproximación a los conceptos, teorías e investigaciones sobre el retorno que facilite la comprensión de los resultados empíricos.

\section{Teorías e investigaciones sobre el retorno}

\section{1. ¿Existe una teoría general del retorno?}

Afirma Castillo (1997: 43) que «hasta el momento presente no se ha desarrollado ninguna teoría capaz de dar cuenta del fenómeno migratorio en su compleja totalidad: sólo se cuenta con teorías aisladas, cuando no contradictorias,

3. La legislación en vigor sobre extranjería, la Ley Orgánica 8/2000, del 22 de diciembre, de reforma de la Ley Orgánica 4/2000, de 11 de enero, sobre derechos y libertades de los extranjeros en España y su integración social (BOE do 23 de diciembre de 2000), así como aquéllas que la completan, regulan todos los derechos y las obligaciones de los extranjeros que han inmigrado a España y que residen en algún lugar del Estado español.

4. Algunas mujeres españolas perdieron su nacionalidad al casarse con hombres de países iberoamericanos que no permitían que ellas conservasen una nacionalidad diferente a la del marido. Esto supuso la pérdida de la nacionalidad española, tanto para estas mujeres como para sus descendientes. Desde el año 2000, en España, se han acelerado los trámites para la recuperación de la nacionalidad española de estas personas. En todo caso, la legislación de nacionalidad para hijos y nietos de españoles nacidos en el extranjero está siendo revisada en la actualidad. 
sobre aspectos parciales del mismo». No existe una «teoría general del retorno», como tampoco existe una única teoría general del fenómeno migratorio. Lo que sí podemos rastrear en investigaciones pasadas son algunos intentos por circunscribir el fenómeno de la emigración de retorno en sus variados aspectos.

Bovenkerk (1974: 5) ya intentó delimitar el concepto de emigración de retorno distinguiéndola de la reemigración (volver a emigrar al mismo país de destino después de haber vuelto a casa), de la nueva emigración (emigrar a un país diferente al que se emigró por primera vez después de haber vuelto a casa), la emigración circular (ir y volver sucesivas veces al mismo país de destino) y la emigración de tránsito (emigrar a un tercer país desde el de la emigración). En esta clasificación, el concepto de "emigración de retorno" alude y se restringe al regreso definitivo del emigrante a su país de origen.

Encuadrado el concepto, no han sido pocos los sociólogos que intentaron establecer «reglas» que explicasen la emigración de retorno, aunque, a juicio de Castillo (1997: 33), éste ha resultado ser un propósito fallido. Según el investigador, los estudiosos no han podido establecer regularidades empiricas sobre el retorno que no sean generalidades ya esbozadas desde las leyes de Ravestein, como que "cada corriente migratoria produce una contracorriente compensatoria» o que aborden un único aspecto del fenómeno sin llegar a establecer un modelo general de interpretación sobre el retorno. Autores como Petersen (1968), George (1970) o, más recientemente, Huntoon (1995), entre otros, intentaron aportar y completar las regularidades básicas de los movimientos migratorios de retorno analizando las diferencias existentes entre emigrantes y no emigrantes, las variantes demográficas en las estructuras de las poblaciones afectadas, los lugares de regreso, el desarrollo económico producido por la emigración, etc. En todo caso, cada investigador incide en uno o en varios de estos aspectos, sin ser capaz de articular una única teoría general de la emigración de retorno que sirva de modelo para comprender cualquier movimiento migratorio de este tipo.

\subsection{Investigaciones sobre el retorno en España}

En España, la mayor parte de los investigadores especializados en migraciones coinciden en la «escasez de estudios sobre el retorno en la amplia y casi inabarcable bibliografía existente sobre los movimientos migratorios» (Vilar, 2003: 263; Hernández Borge, 2003; Egea Jiménez y otros, 2004).

Una de las razones que parece justificar esta insuficiencia de estudios es la «ausencia total o parcial de estadística fiable»(Vilar, 2003: 262) ${ }^{5}$, la escasez de

5. Las fuentes estadísticas más usadas para el análisis de los movimientos migratorios son las altas en los padrones municipales (de los ayuntamientos) desde 1983, explotados y elaborados por el INE en los anuarios estadísticos de España y en la serie «Migraciones». También las estadísticas de variaciones residenciales (EVR), el censo electoral de los residentes ausentes y los censos consulares, quienes aportan estadísticas de bajas consulares. Álvarez Silvar e 
medios para llevar a cabo estos estudios, que, por otra parte, manifiesta el poco interés mostrado hasta la fecha por las instituciones por financiarlos (Izquierdo Escribano y Álvarez Silvar, 1997a: 49) y, añadiríamos nosotras, la indiferenciación, en las propias fuentes estadísticas, de los diferentes grupos «migrantes», al ofrecer conjuntamente datos sobre «extranjeros», sin ser capaces de discriminar, de entre ellos, los emigrantes retornados de segunda y tercera generación descendientes de españoles, que, en un breve plazo de tiempo, son nuevamente «españoles naturalizados».

Con todo, existen algunos estudios empíricos sobre el retorno, ya clásicos para quienes investigan este fenómeno. Izquierdo Escribano y Álvarez Silvar (1997a: 45-74) los han recopilado en un interesante artículo.

La primera encuesta que se conoce en España realizada a emigrantes retornados fue la de Sánchez López en 1969, de carácter estadístico, centrada en el retorno de Europa y que forma parte de un trabajo más amplio destinado a la emigración.

El primer estudio monográfico sobre retornados lo llevó a cabo Pascuals en 1970. En él se valoraba el cambio producido en la conciencia obrera de emigrantes retornados que habían sido trabajadores de la metalurgia en Alemania.

No será hasta la década de los ochenta que el retorno como fenómeno migratorio en si mismo comience a ser analizado. De hecho, Castillo publicaba, en 1980, una encuesta realizada en todo el Estado español sobre los retornados. En 1981, Garmendia dirigía una investigación que completaba el estudio anterior. En realidad, el estudio de Castillo es el único elaborado en todo el territorio español hasta la fecha que incide en el perfil del retornado como persona con rasgos distintivos y diferenciados de aquéllos que nunca fueron emigrantes.

El resto de los estudios recogen aspectos específicos del retorno o bien se limitan a analizarlo en un ámbito territorial concreto. En 1986, De Miguel, Izquierdo, Moral y Bergere Dezaphi desarrollaron un estudio sobre las expectativas de regreso de la emigración española en Europa. También se publicaron trabajos «regionales» o "provinciales». En 1984, apareció un trabajo sobre el retorno en la provincia de Ourense (Galicia), realizado por Pérez Díaz, y, en 1989, Cazorla investigó el retorno en el sur de España en el medio rural.

Ya en la década de 1990, se detecta algún que otro estudio más de ámbito «regional»: uno sobre el retorno a Cantabria (norte de España), de Soldevilla Oria y Rueda (1992); la investigación de González Díaz realizada sobre el retorno a Tenerife (Islas Canarias) en 1993; el trabajo cuantitativo de De la Campa Montenegro, circunscrito a Galicia y a sus municipios (1996), y el trabajo cualitativo de Álvarez Silvar, también llevado a cabo en Galicia en 1996.

Izquierdo Escribano (1997: 55) añaden las estadísticas de las demandas de empleo del Instituto Nacional de Empleo. En Galicia, hay que añadir la publicación de los movimientos migratorios de Galicia desde 1992 publicados por el IGE, que, a pesar de ofrecer altas padronales por municipios, no facilitan características específicas de los retornados. 
El retorno a España también ha sido objeto de interés y de estudio en Europa. A partir de la década de 1980, principalmente en Francia y Alemania, comenzaron a analizarse las razones y las consecuencias del regreso de los emigrantes a sus países de origen. En Francia, Ewnczyk, Garson y Moulier realizaron un estudio para la OCDE sobre el retorno en España, publicado en 1978. Y en Alemania, destacan, entre otros, los trabajos de Berger, Hessler y Kavemann (1978), Bernitt (1981) y Sneider (1983). En 1988, la Organización Internacional del Trabajo encargó a Ardittis un estudio comparado sobre el retorno en España, Grecia, Italia y Portugal (1988).

\subsection{Perspectivas de las investigaciones}

La mayor parte de los estudios llevados a cabo en España relacionados con el retorno han sido realizados desde una perspectiva sociológica o demográfica. Se echan en falta más investigaciones en torno a la integración social de los retornados (laboral, educativa, social, etc.), las cuales aportarían información crucial para planificar intervenciones institucionales para este colectivo desde los sistemas de protección social públicos, como el sistema educativo, el sistema de servicios sociales, el sistema de empleo, etc. En este sentido, faltan estudios realizados desde el trabajo social, la educación social o la medicina, por poner un ejemplo.

La gran mayoría de los trabajos mencionados en el apartado anterior son fruto de datos obtenidos de primera mano (datos de carácter primario) a través de encuestas, entrevistas en profundidad e historias de vida. Estos estudios se completan generalmente con investigaciones que analizan los motivos para el regreso de los emigrantes y diseccionan los escenarios escogidos por éstos para su retorno. Casi todos pretenden ofrecer modelos explicativos del retorno, como veremos más adelante, ofreciendo tipologías del retornado (Cerase, 1974; Álvarez Silvar, 1997b; Durand, 2004; Egea Jiménez, Rodríguez Rodríguez y Nieto Calmaestra, 2004).

\section{Metodología de la investigación}

El método biográfico ha sido poco utilizado para el estudio del retorno en España. Pionero en esta modalidad ha sido Marsal, quien, en 1972, se centró en la historia de vida de un único emigrante catalán retornado de América en situación de precariedad. Más recientemente, ha sido Álvarez Silvar (2001) quien ha desarrollado una investigación biográfica a partir de los relatos personales de cuarenta informantes.

Más próximos todavía se encuentran en el tiempo los estudios cualitativos de Egea Jiménez, Rodríguez Rodríguez y Nieto Calmaestra (2004), en Andalucía, quienes, centrándose en los lugares de retorno de los andaluces, ahondan en las motivaciones para su regreso.

No nos vamos a extender en justificar el porqué de esta elección, ya que puede explicarse de forma breve en palabras de Ruiz Olabuénaga (1999: 279-280): 
Cuatro objetivos principales justifican el uso de la Historia de Vida como método de investigación: Captar la totalidad de una experiencia biográfica, totalidad en el tiempo y en el espacio [...]. Captar la ambigüedad y el cambio: lejos de una visión estática e inmóvil de las personas [...]. Captar la visión subjetiva con la que uno mismo se ve a sí mismo y al mundo [...]. Descubrir las claves de interpretación de no pocos fenómenos sociales de ámbito general e histórico que sólo encuentran explicación adecuada a través de la experiencia personal de los individuos concretos.

Cualquiera de los aspectos mencionados por Ruiz Olabuénaga nos pareció idóneo para justificar el uso del método biográfico en esta investigación: en primer lugar, nos parecía sumamente interesante que los informantes pudieran contraponer y valorar subjetivamente hechos nucleares de su migración: la salida al país de destino y el regreso al país de origen; el principio y el final del proyecto migratorio.

En segundo lugar, por seguir el orden de Ruiz Olabuénaga, nos pareció particularmente relevante captar los cambios experimentados por los protagonistas de los relatos a lo largo del tiempo y del espacio de su migración, así como la ambigüedad tan presente en cada una de las historias recogidas, expresadas en contraposiciones permanentes, en binomios que parecen alterar la narración —ora positiva, ora negativa—, aquí y allá, sin llegar a estabilizar el discurso de un lado o de otro en un balance final, en una elección imposible para personas escindidas entre dos mundos. El relato biográfico manifiesta, en este sentido, todo su potencial.

En tercer lugar, nos interesa acercarnos a la experiencia de la emigración de retorno, interpretando las autobiografías producidas por los propios sujetos informantes, en un formato metodológico en donde el investigador utiliza los textos sin poner en tela de juicio la exactitud o la veracidad del relato, ya que no se trata de analizar su "verdad», sino de ampliar la comprensión de una realidad social amplia, tal y cómo es vivenciada y sentida por sus protagonistas (Denzin, 1989).

En cuarto lugar, deseábamos abordar el fenómeno de la emigración de retorno dando especial importancia a los aspectos emocionales y psicosociales de este proceso, aspectos muchas veces silenciados en las investigaciones, en especial las cuantitativas, en favor del análisis de aspectos considerados de mayor trascendencia, como la formación y la capacitación laboral, la integración en el trabajo, las ayudas a los retornados, etc.

En este sentido, los relatos de vida son narraciones autobiográficas sobre experiencias personales que poseen un interés profundo y duradero para los narradores, contadas a través de sus propias voces (Chase, 1995) y que aportan, como señala Pujadas (1992), una evidencia fundamentalmente cualitativa sobre la percepción del informante acerca de cierto acontecimiento o problema.

Dicho esto, podemos definir la investigación llevada a cabo como un estudio cualitativo transversal desarrollado mediante el enfoque biográfico-narrativo. La historia de vida como técnica se ha usado porque consideramos que 
nos iba a permitir comprender mejor las vivencias subjetivas de los protagonistas, con el objetivo último de que fuesen estas personas las que manifestasen las dificultades sufridas y los puntos de inflexión vividos en su migración.

El proceso de categorización de la información se llevó a cabo fragmentando el texto en elementos particulares y separando los contenidos de los relatos en torno a los tópicos más reiterados en los relatos de vida que fuesen relevantes para la investigación.

Se obtuvo un mayor grado de sistematización de la información a partir del análisis de los elementos temáticos identificados en la fragmentación del texto. La codificación de la información por criterios temáticos favoreció una comprensión más profunda del objeto de este estudio: el retorno y su impacto psicosocioemocional.

Las categorías seleccionadas se examinaron a través de procedimientos cualitativos de análisis de contenido y se complementaron con la recogida estadística de sus frecuencias y porcentajes (Rodríguez, Gil y García, 1999). La fiabilidad de las codificaciones de las categorías fue debatida con un grupo de investigadores que colaboran en el proyecto (Goetz y LeCompte, 1988).

\subsection{Participantes}

Los informantes que participaron en esta investigación fueron seleccionados a partir del contacto con asociaciones de emigrantes retornados que existen en Galicia, en concreto, asociaciones de las provincias de Pontevedra y Ourense. También fueron localizados a través de un servicio municipal denominado Oficinas de Atención al Inmigrante, que asisten, entre otras poblaciones, a los emigrantes retornados pertenecientes a la comunidad autónoma gallega.

De entre las personas localizadas, la población objeto de esta investigación se redujo a aquellos emigrantes retornados de segunda y de tercera generación, con independencia de si legalmente son extranjeros, españoles o naturalizados como españoles.

La recogida de datos se fue simultaneando con el análisis y la valoración de los mismos en un proceso interactivo que sirvió, así mismo, para determinar en qué momento podía detenerse la recogida de información (Miles y Huberman, 1984).

Se utilizaron, siguiendo estas pautas metodológicas, cuarenta y nueve relatos de vida, cuyos datos brutos, por una parte, y la reducción de los mismos, por otra, estableció la determinación de su suficiencia en función de la saturación de los datos obtenidos.

Los cuarenta y nueve relatos de vida se obtuvieron de forma individual en un ambiente planificado para que fuese distendido y que los participantes ofreciesen, en sus relatos, toda la información considerada relevante por ellos en su proyecto migratorio.

Cada entrevista fue grabada por completo en audio, previa autorización de cada informante. La duración de cada entrevista osciló entre los cuarenta y cinco y los sesenta minutos. 
Las entrevistas fueron transcritas al papel, para poder ser analizadas y obtener una mejor categorización de la información obtenida. Las transcripciones respetaron el idioma original de los informantes (el castellano y el gallego), así como las variedades dialectales del gallego y las incorrecciones del idioma, derivadas, en muchos casos, del uso prolongado durante largo tiempo de otras lenguas y de otras estructuras gramaticales. Para una mayor comprensión de los relatos, hemos traducido al castellano todas las intervenciones de los informantes, aunque hemos respetado los usos gramaticales de éstos, aun cuando sean incorrectos en español.

La investigación, por último, cuidó con detalle el anonimato de los sujetos informantes y aquellos otros datos que pudieran revelar la identidad de los entrevistados.

\subsection{Determinación de las categorías}

Los resultados obtenidos en esta investigación han sido expuestos en dos grandes apartados: en primer lugar, se ofrece un perfil «básico» de los entrevistados (edad, sexo, edad en el momento del retorno, etc.). Por otra parte, se presentan las diferentes categorizaciones a partir de las cuales se ha reconstruido, en este artículo, el relato en torno al proyecto migratorio de los emigrantes retornados protagonistas del estudio.

\section{Resultados de la investigación}

\subsection{Perfil del emigrante retornado de segunda generación en Galicia}

La mayor parte de los emigrantes retornados que formaron parte de esta investigación son hijos de emigrantes (segunda generación) y solamente en dos casos son nietos de gallegos.

Las edades actuales de los entrevistados oscilan entre los veinte y los ochenta y dos años, aunque solamente seis son mayores de sesenta años y el grupo más numeroso se sitúa en la franja que va de los veinte a los veinticinco años (quince personas).

En lo que respecta al sexo, la mayor parte de las personas que forman parte de este estudio son mujeres (treinta y cinco), frente a catorce hombres.

La mayor parte de estos emigrantes retornados de segunda generación nacieron en el país de emigración de sus padres o emigraron siendo bebés, con menos de doce meses de edad (veinte); un número considerable emigró entre el primer año de vida y los diez años (doce). En este estudio, por lo tanto, hay treinta y dos personas emigradas desde su infancia y diecisiete que emigraron con más de once años. De éstas últimas, la inmensa mayoría emigró antes de los veinte años (quince) y sólo dos personas tenían más de veintiún años en el momento de salir de su país.

Estos datos van a ser especialmente relevantes, dado que muchos de los informantes manifiestan una profunda impronta en sus vidas por el hecho 
de haber sido emigrantes, aún cuando su regreso se produjo a muy corta edad.

El nivel de estudios alcanzado a lo largo de la vida de estas personas es mayoritariamente de «nivel básico». Han realizado los estudios obligatorios treinta y tres personas, seis finalizaron estudios «secundarios», bien en formación profesional o bien en bachillerato, y solamente ocho accedieron y/o terminaron estudios universitarios.

Los países receptores de estos emigrantes se pueden agrupar fundamentalmente a partir de dos continentes: Europa y América (central y del sur). De Europa, proceden veintisiete de los entrevistados, mientras que de América regresaron veintiuno y de Australia volvió una persona. En Europa, los países de acogida fueron, por orden de importancia: Suiza (once), Francia (nueve), Alemania (seis) y Bélgica (uno). En cuanto a América, los principales países receptores de emigrantes gallegos fueron Venezuela (once) y Argentina (cuatro), seguidos de lejos por México (dos), Chile (dos), Cuba (uno) y Colombia (uno).

Sin entrar todavía en los motivos del regreso de estos retornados, aspecto sobre el cual se volverá en breve, se puede apreciar que la mayor parte de los entrevistados regresó a Galicia antes de los veinte años (veintisiete), en segundo lugar, por orden de importancia, apreciamos un número considerable de regresos producidos entre los veintiún y los cuarenta años (diecinueve), mientras que sólo tres personas retornaron después de haber cumplido cuarenta y un años.

\subsection{Valoración del proyecto migratorio de los retornados}

\subsubsection{Motivaciones para la emigración}

Dado que el estudio se ha realizado con emigrantes retornados de segunda generación, muchos de los cuales nacieron en el país de emigración de sus padres o fueron llevados allí siendo niños, las motivaciones para haberse marchado de Galicia aluden en su mayoría a las razones de sus progenitores para emigrar, y, en algunos casos, en especial en los relatos de algún emigrante retornado de América, esgrimen razones políticas, aunque la mayor parte subraya la crisis económica que sufría España desde la Guerra Civil (1936-1939):

Como tengo cuarenta años y me llevaron con once meses..., pues en realidad yo no he elegido irme, ni que me llevasen, simplemente las circunstancias. (M27)

Bueno, mis padres marcharon a Venezuela porque aquí no había trabajo, estaban recién casados, tenían un niño y decidieron irse para Venezuela, a probar allí..., que tenían una oportunidad. (H41)

En realidad, en este estudio fueron pocos los entrevistados que tomaron la decisión de emigrar por sí mismos. Este hecho, la imposibilidad de escoger si 
quedarse en su país o marcharse de él, provoca sentimientos de impotencia, rabia y frustración en gran parte de los entrevistados; especialmente en aquéllos que emigraron a edades adolescentes y que, si bien no podían imponer sus preferencias a las de sus padres, ya tenían edad para sufrir con plena conciencia el hecho de tener que marcharse:

Que conste que fui obligada, no me gustó, de vacaciones sí; pero..., es muy frío, ya no el clima, sino la persona... No, nunca me gustó. (M4)

\subsubsection{Motivaciones para el retorno}

En el momento del retorno, a los entrevistados les ocurrió, en gran parte, lo mismo que en la etapa inicial de su proyecto migratorio. Ya que la mayoría de los informantes eran hijos de emigrantes que retornaron a Galicia a una edad temprana, pocos pudieron realmente decidir sobre el hecho de regresar o de planificar su regreso.

Las razones para retornar son atribuidas, por lo tanto, a los progenitores. Además, los entrevistados procedentes de países de América ponen de manifiesto la crisis económica y la inseguridad:

[...] y allí era muy peligroso ya estar allí. Entonces nos decidimos, por seguridad, venir a vivir a España, bueno, decidieron mis padres... y aunque viviéramos un poco peor, pues vivíamos más tranquilos por motivos de seguridad, y lo que más me chocó fue que aquí podíamos andar más en la calle y hasta la noche sin ningún tipo de problema, cosa que allí no podíamos. (H41)

Los motivos para el retorno desde los países europeos suelen ser básicamente dos: al final del proyecto migratorio, con el regreso en la etapa de la jubilación, o un regreso anticipado producido por cuestiones económicas o familiares:

El motivo de su regreso fue porque añoraban vivir aquí de nuevo y todo el dinero que habían ahorrado lo habían usado también para hacer una casa aquí [...] Sentían que su vida ya no tenía sentido allá: mi padre estaba en el paro, porque estuvo muy enfermo, y mi madre ya no trabajaba, porque siempre había trabajado sin papeles y entonces decidieron pasar el resto de su vida tranquilos. (M29)

A los veintidós años decidí venirme para España, mis padres se vinieron conmigo, ya que cogieron la jubilación (M35)

La vuelta al lugar de origen sin el consentimiento expreso o consensuado de los descendientes, provocó que gran parte de los entrevistados afrontasen el retorno con incomodidad e incluso con una clara oposición:

Yo estuve viviendo allí dieciséis años y yo no quería venir para aquí, porque, claro, al estar allí hasta los dieciséis años, pues tu siempre te haces a donde naces 
y estás con la gente con la que te criaste y, claro, yo allí lo tenía todo: tenía amigos, ya empezaba a salir un poco, conocía a muchísima gente, ya me hice a ese país, a esa ciudad y, nada, a los deiciséis años me tuve que venir para aquí. ( H22)

Con todo, en ocasiones, la vuelta al país de origen se produjo por voluntad propia o con el acuerdo expreso de los descendientes:

Yo necesitaba un cambio, tenía ganas de un cambio y entonces fuimos de vacaciones, bueno hacia los quince años, o sea que estoy aquí desde hace cinco años y tenía ganas de saber dónde están mis raíces. (M34)

\subsubsection{Dificultades del retorno: idioma, títulos, trabajo}

Además de los problemas de adaptación relatados al principio de la llegada, relativos al propio regreso, otras problemáticas y dificultades asaltan las vidas de los emigrantes retornados de segunda generación: los manifestados aluden principalmente al idioma, a la convalidación de los estudios (formación profesional y carreras universitarias) y, en menor medida a la integración laboral.

La vuelta lo pasé muy mal. Yo no me quería venir de allí. No sabía el castellano, sólo hablaba el francés. ¡Cuánto lloraba yo la noche antes de venirnos! Todavía me acuerdo. (M26)

No tuve mucha suerte con mis estudios, porque vine con una carrera y no me la convalidaron [...] o sea que tiré por la borda todos mis estudios y me quedé de ama de casa. (M1)

Esta dificultad de convalidación de estudios afecta a la inserción laboral, de modo que muchos de ellos optan por crear un negocio familiar con los ahorros adquiridos.

Así que no me quedó más remedio que poner un negocito que me diese para comer. Al principio, como no había tantos centros comerciales, fue bien, pero después otra vez a reorganizarme. (H15)

También tienen problemas para el acceso a la vivienda. En muchos casos, los bienes paternos han sido vendidos o cedidos por el cuidado de los abuelos a la familia extensa. Esta situación, junto a la escasez de bienes económicos y al tiempo que tardan en encontrar trabajo al tener que legalizar su situación, dificulta mucho la posibilidad de acceder a una buena vivienda de alquiler. La solución, en muchos casos, la encuentran en la ayuda prestada por distintas organizaciones no gubernamentales, que se hacen cargo de estos gastos durante un tiempo.

Lo tuvimos muy complicado al llegar. Gastamos los ahorros en el pasaje y necesitábamos tener algún remanente para la comida. No queríamos abusar de la familia. Así que solicitamos a Caritas una ayuda para la casa y yo me puse 
a trabajar de empleada de hogar, ilegal, claro. Mi marido hacía chapuzas de electricidad. Ahora ya tenemos los papeles en regla. Hemos querido devolver el dinero. La verdad, estamos muy agradecidos por la ayuda. Tuvimos suerte. No es el primero que se tiene que volver. (M7)

\subsubsection{Dificultades emocionales del retorno: identidad, desarraigo, separación} Los informantes, como todos los emigrantes, retornados o no, parecen en su mayoría atrapados entre dos mundos, dos culturas, dos identidades, y en pocas ocasiones resuelven esta dicotomía de forma satisfactoria para ellos. Uno de los tópicos permanentes entre los entrevistados es su necesidad de "comparar» los países en donde vivieron para "escoger» uno de ellos... Valoran las ventajas y las desventajas de sus lugares de residencia y, en muchas ocasiones, el país de la emigración les parece «mejor» que el del retorno.

Cuando vinimos para España, mi marido encontró trabajo y no volvimos a Suiza, pero la vida de Suiza era una maravilla... (M21)

A mí me gustaba más en Suiza todo en general. (M16)

Mi situación ahora mismo, aquí, es buena, pero era mejor en Venezuela. (M17)

Esta permanente "comparación» lleva a los entrevistados a reflexionar sobre su "pertenencia» a un lugar u otro de su emigración. También aquí manifiestan dudas y ambigüedades. "Ser» de un país, "sentir» una cultura, «adquirir» una identidad, genera, en la mayor parte de los entrevistados, inquietud y desasosiego. Hablar de la identidad les resulta realmente complejo e incluso confuso:

Cuando estoy en España, es que me siento francesa y, cuando estoy allá, en Francia, me siento española. No sé, bueno, perdón, también me siento gallega, tengo unas culturas ahí metidas... Yo que sé, no es muy extraño, pero hace parte de mi identidad... (M34)

Hemos apreciado, en los relatos, la sensación de algunos retornados de haber abandonado el país "propio", aunque ahora estén viviendo en el país de origen. Estos sentimientos perturban a los entrevistados y, en definitiva, vuelven a poner de manifiesto el desarraigo que sufren. En definitiva, explicitan las dificultades de adaptación de la población retornada:

Ahora, después de casi cuatro años, nos hemos podido comprar dos billetes para Argentina y no veo la hora de regresar a mi barrio, con mi gente y mi familia. Aunque sin poderlo pensar cuando vine, mi corazón está dividido entre mi familia argentina y mi familia española. (M12)

En todo caso, la propia experiencia de emigrar de aquí para allí y de allí para aqui sitúa a los retornados en un espacio en el cual se sienten permanentemente extranjeros aún en su propia tierra: 
Hoy en día soy española y tengo las costumbres y valores de una persona gallega..., pero creo que, si fuese a Venezuela, me sentiría como una emigrante en mi propio país de nacimiento. Hecho que les sucedió a los propios emigrantes que se fueron allí e hicieron su vida en ese lugar y allí eran inmigrantes, y, cuando regresaban a Galicia, eran también considerados extranjeros, porque estaban a medio camino entre aquello y esto. Por eso considero que, para todos los emigrantes, esto es una de las cosas más duras que supone la emigración. (M18)

De hecho, conocen algunas costumbres culturales mejor que otras personas de su misma edad que han vivido siempre aquí:

Yo sé bailar la muiñeira, hacer cocido o sembrar y recoger el maíz mejor que muchas personas de mi edad que nunca han salido de aquí. Mi madre nos obligaba a mis hermanos y a mí a saber de todo, y nuestras reuniones, hasta que fuimos mayores, sólo eran con gallegos y para hablar en gallego ¡claro! de las cosas de aquí. (M8)

Si la identidad —o la sensación de no poseer identidad alguna — es una de las peculiaridades de los retornados, otra de las características que los definen es el dolor que sufren por el desarraigo y la separación de sus seres queridos.

Encontramos, en las historias de vida de los informantes, alusiones a los problemas de adaptación familiar, social y cultural, pero, de forma habitual, sobresale una temática reiterada por parte de la mayoría de los retornados: el dolor que produce la separación entre los miembros de la familia, en especial, entre padres e hijos, aunque también se expresa la ausencia de los hermanos:

Cada vez que lo recuerdo, aún se me rompe el alma... No hay dolor tan grande como no poder criar a un hijo, ni verlo crecer [...] Mira, por mucho que piense la gente que nos puede comprender, nadie jamás sentirá lo que una madre lejos de sus hijos, y unos hijos lejos de los padres. Non hay dinero que pague eso... Non lo hay. (M45)

Vine de retorno con mi hijo de seis años y quedó toda mi familia allí [pausa emocionada] y bueno, casi me fue más difícil ahora de vuelta adaptarme y volver otra vez a ser extraña en mi país. (M1)

Tengo allá a mis hermanas y siento mucha morriña de mi país [mal del país] y, si me dejaran escoger, escogería irme para Venezuela y no estar aquí. (M17)

\section{Conclusiones}

La investigación pretendía mostrar cómo expresan y cómo afrontan el hecho de la emigración de retorno algunos de sus protagonistas. Hemos podido constatar que estos descendientes de gallegos suelen tener problemas con la convalidación de sus títulos académicos, con el acceso a la vivienda propia y con 
la incorporación al mercado de trabajo. Además, las expectativas de su proyecto migratorio no siempre se ven cumplidas y muchos manifiestan problemas de adaptación en un país que no resulta ser como imaginaban. La imagen del país se forma a partir de los relatos de sus padres y de la transmisión de las costumbres culturales en sus propias familias.

A diferencia de los hijos y de los nietos de emigrantes retornados de Europa, el grupo de retornados iberoamericanos no suele haber tenido demasiado contacto con Galicia antes de su llegada, si es que alguna vez tuvieron ese contacto básico. Sus padres no solían venir de vacaciones a Galicia y las visitas - cuando se producían - eran absolutamente excepcionales. Incluso, en ocasiones, estos emigrantes perdieron el contacto completo con toda la familia de origen. Por lo tanto, muchos de estos retornados de segunda generación pisan Galicia por primera vez en sus vidas, en lo que para ellos es un proceso migratorio de ida, ya que, en sentido estricto, no se puede regresar de un lugar en el cual nunca se estuvo con anterioridad.

Este último grupo de «retornados», que es tal y como los reconoce la legislación española, a efectos de análisis social, comparten en gran medida sus características y problemáticas con cualquier otro inmigrante - extranjero o no- del Estado español.

En nuestra opinión, los retornados de segunda generación van a vivir mayores problemas que aquéllos con los que se enfrentan sus progenitores. La integración social y laboral, las dificultades de adaptación, el desarraigo, la pérdida de identidad van a acompañarles, al igual que a sus padres décadas antes, y deberán construirse un espacio propio en un país desconocido para ellos o mal conocido a través de los relatos de sus familias.

$\mathrm{La}$ intensidad de los relatos pone de manifiesto la relevancia que tienen para las personas los movimientos migratorios en los cuales se han visto involucrados, aunque haya sido por un corto espacio de tiempo. También se evidencia el impacto emocional que les ha provocado a los retornados su proceso migratorio de ida y vuelta y, como en muchas ocasiones, este hecho sigue siendo uno de los que más ha marcado sus vidas.

El perfil descrito nos permite diseñar programas que faciliten la integración social y laboral del emigrante retornado y proponer estrategias que minimicen o reduzcan los sentimientos de pérdida o desarraigo.

\section{Referencias bibliográficas}

ÁlVAREZ SiLVAR, Gabriel (1996). La migración de retorno en Galicia (1979-1995). Tesis doctoral. Dos tomos. Madrid: Universidad Complutense.

- (1997a). La migración de retorno en Galicia (1970-1995). Santiago de Compostela: Xunta de Galicia.

- (1997b). «Las organizaciones de retornados en Galicia». Migraciones, 2, p. 213234.

- (2001). De volta ao Lar. Relatos de vida sobre a emigración. A Coruña: Edicios do Castro. 
ARDitTIS, Solon (1988). Migration de retour en Europe du Sud. París: Organisation Internationale du Travail.

Berger, Hartwig; Hessler, Manfred y Kavemann, Barbara (1978). Brot für heute, Hunger für morgen. Landarbeiter in Südspanien. Frankfurt: Ein Sozialbericht.

BERNITT, Marion (1981). «Die Rückwanderung spanischer Gastarbeiter-Der Fall Andalusien». Materialien zur Arbeitsmigration und Ausländerbeschäftigung, 7, Königstein/Ts.

BlanCO, Cristina (2000). Las migraciones contemporáneas. Madrid: Alianza Editorial.

BOVENKERK, Frank (1974). The sociology of return migration. La Haya: Martinus Nifhoff.

Campa Montenegro, Ildefonso de la (1996). Informe sobre el retorno en los municipios de Galicia. Santiago de Compostela: Xunta de Galicia.

Campo, Salustiano del (1993). Tendencias sociales en España (1960-1990). Vol. III. Bilbao: Fundación BBV.

CASTILlO, José (1980). La emigración española en la encrucijada: Estudio empírico de la emigración de retorno. Madrid: Centro de Investigaciones Sociológicas.

- (1997). «Teorías de la migración de retorno». En: IZQUIERDO, A. y ÁlVAREZ SILVAR, G. (coords.). Politicas de retorno de emigrantes. A Coruña: Universidad de A Coruña, p. 29-44.

CAzOrla Pérez, José (1989). Retorno al Sur. Madrid: Oficina de Coordinación de Asistencia a Emigrantes retornados de Cádiz / Siglo XXI.

Cerase, Francesco P. (1974). «Migration and social Change: Expectations and Reality. A case study of return migration fron the United States to Southern Italy». International Migration Review, 8 (2), p. 245-262.

CHASE, Susan E. (1995). «Taking narrative seriously: Consequences for method and theory in interview studies». The Narrative Studies of Lives, 3 (1), p. 1-26.

CriAdo, María Jesús (2001). La línea quebrada: Historias de vida de migrantes. Madrid: Colección Estudos.

DenZIN, Norman K. (1989). Interpretative biography. Newbury, CA: Sage.

DURAND, Jorge (2004). «Ensayo teórico sobre la migración de retorno. El principio del rendimiento decreciente». Cuadernos Geográficos, 35, p. 103-116.

EGEA JiMÉNEZ, Carmen y RodrígueZ RodríGUEZ, Vicente (2004). «Tipos de retorno de los emigrantes jubilados. El caso de los emigrantes da provincia de Jaén». En: Actas del VII Congreso de la Asociación de Demografia Histórica. Granada, 1 al 3 de abril.

EWNCZYK, Pierre; GARSON, Jean-Pierre y MOULIER, Yann (1978). Retour et developpement: l éxemple espagnol 1960-1978. París: Fondation Nationale des Sciences Politiques.

GARMENDIA, José Antonio (ed.) (1981). La emigración española en la encrucijada. Marco general de la emigración de retorno. Madrid: CIS.

GEORGE, Peterson (1970). "Types of migration of the population according to the professional and social composition of migrants». En: CliffORD JOHN, J. (ed.). Readings in the sociology of migration. Oxford: Pergamon Press, p. 39-49.

Goetz, Judith Preissle y LeCOMPTE, Margaret D. (1988). Etnografía y diseño cualitativo en investigación educativa. Madrid: Morata.

GONZÁLEZ DíAZ, Elliot (1993). «Migración de retorno y cambio económico en el sur de Tenerife». En: Actas de las IV Jornadas de la Población Española. Tenerife: Universidad de La Laguna, p. 89-93.

Hernández Borge, Julio (2003). «La inmigración exterior en Galicia». Papeles de Geografia, 37, p. 155-164. 
HunTOON, Laura (1995). «Return Migration whwn savings differ». Journal of Urban Affairs, 17 (3), p. 219-239.

IzQUIERDO, Antonio y ÁlVAREZ SILVAR, Gabriel (1997). «Estado actual da investigación sobre el retorno». En: IzQUierdo, A. y Álvarez SiLVAR, G. (coords.). Políticas de retorno de emigrantes. A Coruña: Universidade de A Coruña, p. 45-74.

MarTíneZ, Paola (2007). «Empresas familiares de inmigrantes». Papers, 85, p. 229-31.

Miguel, Amando de; IzQuierdo, Antonio; Moral, Félix y Bergere DezAPHI, Joellle Annie (1986). Panorama de la emigración española en España. Madrid: Ministerio de Trabajo y Seguridad Social.

Miguel CASTAÑo, Carmen (2000). «Inmigración, demografía y políticas de integración». En: Garde, J. A. Informe 2000. Políticas sociales y Estado de Bienestar en España. Madrid: Fundación Hogar del Empleado.

Miles, Matheu B. y Huberman, A. Michael (1984). Qualitative data analysis: A sourcebook of new methods. Newbury Park, CA: Sage.

PASCUAL DE SANS, Ángels (1970). El retorno de los emigrantes. Barcelona: Nova Terra.

PÉREZ Díaz, Victor (1984). La emigración en la provincia de Ourense: el retorno y sus perspectivas. Ourense: Caixa Ourense / Sotelo Blanco.

PETERSEN, William (1968). La población: un análisis actual. Madrid: Tecnos.

Poirier, Jean; Clapier-Valladon, Simona y Raybaut, Paul (1995). Historias de vida. Teoría y práctica. Celta Editora: Ociras.

PujadAS MuÑoz, Juan José (1992). El método biográfico: el uso das historias de vida en ciencias sociales. Madrid: Centro de Investigaciones Sociológicas.

RodríGuez GÓMEZ, Gregorio; GIL Flores, Javier y GARCía JiMÉNEZ, Eduardo (1999). Metodología da investigación cualitativa. Málaga: Aljibe.

Ruiz OlabúEnaGa, José Ignacio; Ruiz VieYtez, Eduardo Javier y Vicente Torrado, Trinidad Lourdes (1999). Los inmigrantes irregulares en España: La vida por un sueño. Bilbao: Universidad de Deusto.

SÁNCHEZ LópeZ, Francisco (1969). Emigración española a Europa. Madrid: Confederación Española de Cajas de Ahorro.

SCHNEIDER-SÁnChez MARTín, Maria (1983). Emigración y retorno. Tesis de Diploma en Sociología. Universidad de Bremen.

SOlDEvilla ORIA, Consuelo y RUEDA, Germán (1992). «El retorno: nuevo proceso de emigración y adaptación». En: SOldevilla Oria, C. y RuedA, G. Cantabria y América. Madrid: Mapfre, p. 291-314.

VILAR, Juan Bautista (2003). «El retorno en las migraciones españolas en Europa en el siglo XX: Precisiones conceptuales y anotaciones bibliográficas». Papeles de Geografia, 37, p. 261-276. 